\title{
Golgi Cells Operate as State-Specific Temporal Filters at the Input Stage of the Cerebellar Cortex
}

\author{
Shane A. Heine, ${ }^{1}$ Stephen M. Highstein, ${ }^{2}$ and Pablo M. Blazquez ${ }^{1}$ \\ ${ }^{1}$ Department of Otolaryngolgy, Washington University, St Louis, Missouri 63110, and ${ }^{2}$ Marine Biological Laboratory, Woods Hole, Massachusetts 02543
}

Cerebellar processing of incoming information begins at the synapse between mossy fibers and granule cells, a synapse that is strongly controlled through Golgi cell inhibition. Thus, Golgi cells are uniquely positioned to control the flow of information into the cerebellar cortex and understanding their responses during behavior is essential to understanding cerebellar function. Here we show, for the first time, that Golgi cells express a unique oculomotor-related signal that can be used to provide state- and time-specific filtering of granule cell activity. We used newly established criteria to identify the unique electrophysiological signature of Golgi cells and recorded these neurons in the squirrel monkey ventral paraflocculus during oculomotor behaviors. We found that they carry eye movement, but not vestibular or visual, information and that this eye movement information is only expressed within a specific range of eye positions for each neuron. In addition, simultaneous recordings of Golgi cells and nearby mossy fibers revealed that Golgi cells have the opposite directional tuning of the mossy fiber(s) that likely drive their responses, and that these responses are more sluggish than their mossy fiber counterparts. Because the mossy fiber inputs appear to convey the activity of burst-tonic neurons in the brainstem, Golgi cell responses reflect a time-filtered negative image of the motor command sent to the extraocular muscles. We suggest a role for Golgi cells in the construction of forward models of movement, commonly hypothesized as a major function of the cerebellar cortex in motor control.

\section{Introduction}

The cerebellar cortex is among the most well studied brain structures in terms of its microanatomy and synaptic connections, yet its function is still unknown. Past studies have revealed that the cortical circuit includes several distinct classes of excitatory and inhibitory interneurons whose influence is distributed among three layers: an input (granular) layer, an intermediate processing (molecular) layer, and an output (Purkinje cell) layer (Ramon y Cajal, 1911). The input layer is primarily occupied by granule cells, which receive glutamatergic input via mossy fibers projecting from other brain areas. The granule cells in turn provide the major glutamatergic input to Purkinje cells, which are the output neurons of the cerebellar cortex. Interspersed between this input and output is a rich network of GABAergic interneurons that influence signals at various stages in the circuit. Given all that we know about the circuit, it is astounding that the connection between form and function has not yet been made. One reason for this may be the paucity of data on the responses of the interneurons in alert animals, which has held back efforts to determine the processing that is performed by the cerebellar cortex during movement. However, definitive identification of one specific class of interneuron in the alert animal has recently become fea-

Received July 6, 2010; revised 0ct. 12, 2010; accepted 0ct. 18, 2010.

This work was supported by National Institutes of Health Grants R01NS065099 (to S.A.H. and P.M.B.), R01EY05433 (to P.M.B. and S.M.H.), and T32GM08151 (to S.A.H.). We thank Pat Keller for help with the histology; Krystal Henderson, Darryl Craig, and Valentin Militchin for technical assistance; and Dora Angelaki, Larry Snyder, Angel Pastor, and Jennifer Sodini for helpful comments on the manuscript.

Correspondence should be addressed to Pablo M. Blazquez, 4566 Scott Avenue, St Louis, M0 63110. E-mail: pablo@pcg.wustl.edu.

DOI:10.1523/JNEUROSCI.3513-10.2010

Copyright $\odot 2010$ the authors $\quad 0270-6474 / 10 / 3017004-11 \$ 15.00 / 0$ sible: the Golgi cell (Simpson et al., 2005; Holtzman et al., 2006; Barmack and Yakhnitsa, 2008). Golgi cells are the main GABAergic interneurons influencing the input layer. They primarily receive inputs from mossy fibers and granule cell axons (parallel fibers) and strongly inhibit thousands of granule cells via an impressive axonal arborization (Eccles et al., 1964) (see Fig. 3A). Because all signals carried by the mossy fiber inputs must pass through the input stage, it is essential to understand how these signals are shaped by Golgi cell inhibition.

One potentially fruitful way to investigate the role of Golgi cell inhibition may be to consider what signal transformations are required within the cerebellar cortex, given the signals present at the inputs and the outputs of the structure. A hint of the signal transformations performed in the cerebellar cortex is suggested by a contemporary modeling approach to movement control; this approach suggests that the cerebellar cortex performs neural computations necessary for the construction of internal models for motor control (Pasalar et al., 2006; Ebner and Pasalar, 2008). For the oculomotor system, mounting evidence suggests that the cerebellum computes an internal representation of the eye movement (forward model) from an efference copy of the motor command. The output of the forward model is thought to be reflected in the target neurons of ventral paraflocculus (VPFL) Purkinje cells, but not in the eye movement input neurons to the VPFL (Ghasia et al., 2008). If this is true then the signal transformations necessary to compute a forward model of the movement would need to occur within the cerebellar cortex and would most likely involve interneurons such as Golgi cells.

We studied Golgi cells in the VPFL of the alert squirrel monkey during a variety of vestibular and oculomotor behaviors and provide the first evidence of a specific role of Golgi cells in filter- 
ing mossy fiber granule cell throughput temporally and based on the state of the motor system. These results may have implications for the implementation of forward models within the cerebellum.

\section{Materials and Methods}

Subjects and surgery. Four adult squirrel monkeys (Saimiri sciureus; three males, one female) were used for these experiments, two of which were trained in oculomotor tasks $(083,087)$ and two of which were behaviorally naive $(066,078)$. Surgery was performed aseptically under $1-2 \%$ isoflurane anesthesia to implant a scleral search coil for monitoring eye position and a stainless steel post for head restraint. After the monkeys were initially trained (two monkeys) or acclimated to head restraint (two monkeys), a second surgery was performed to implant a stainless steel recording chamber aimed at the cerebellar floccular complex. Additional details of the surgical procedures have been described previously (Blazquez et al., 2003). Ninety percent of the neurons reported here come from the two trained monkeys, with the remaining data from untrained monkeys confirming the general applicability of the results. All procedures conformed to the National Institutes of Health Guide for the Care and Use of Laboratory Animals and were approved by the Washington University Institutional Animal Care and Use Committee.

Neural recording. Single unit and multiunit recordings were made in the cerebellar flocculus using 2-5 M $\Omega$ tungsten electrodes (FHC). The raw signals were amplified, bandpass filtered between $100 \mathrm{~Hz}$ and $8 \mathrm{kHz}$ using eight-pole filters, and digitized at $40 \mathrm{kHz}$ using a Power 1401 and Spike2 software (CED). Spike times of single units were detected online using a time-amplitude window discriminator (Bak) and were recorded digitally as time stamps. Spikes were always resorted offline before analysis using Spike2 template matching and principal component analysis routines. Eye position, laser position, and chair and drum positions were sampled at $500 \mathrm{~Hz}$ using the same Power 1401.

Recordings were confined to the ventral paraflocculus, which was recognized by its typically strong saccade-related hashing and was verified by histological track reconstruction. Golgi cells were identified based on established criteria, as discussed in the Results section. Briefly, these criteria include localization in the granular layer, large spike waveforms with wide spike widths that often remain isolated for $>100$ micrometers of electrode travel, tonic and often extremely regular firing rates, and lack of complex spikes.

Behavioral protocols. Head-restrained monkeys were comfortably seated in a primate chair mounted atop a vestibular table. Oculomotor training consisted of a standard water restriction protocol to motivate the monkey to fixate and pursue a projected laser for liquid reward. Response modality of Golgi cells (i.e., eye movement, vestibular, or visual) was determined by having the monkey fixate or pursue a sinusoidally moving $\left(0.2,0.4\right.$, or $0.5 \mathrm{~Hz} ; \pm 5,8$, or $\left.10^{\circ}\right)$ green laser projected on a screen $60 \mathrm{~cm}$ in front of the monkey under one of three conditions: 1) smooth pursuit, in which the head was held stationary while the laser moved; 2) vestibuloocular reflex (VOR) suppression (VORS), in which the laser was rotated in phase with the chair and the monkey was required to cancel its VORS; or 3) fixation during whole-field stimulation (F-WFS), in which the laser and head were held stationary and the monkey was required to maintain fixation on the laser spot during movement of a patterned background.

During the free-viewing condition, monkeys were turned around such that they faced the experimental room instead of the screen and were encouraged to make eye movements throughout their oculomotor range by the experimenter placing objects of interest at varied horizontal and vertical positions relative to the monkey.

Data analysis. All data were imported to Matlab using the SON Library and analyzed in Matlab (Mathworks) using custom written routines. Spike times were converted to instantaneous firing rates (IFR) by taking the reciprocal of the interspike intervals. Multiunit activity was analyzed by rectifying the raw extracellular waveform and smoothing it with a moving average filter ( $10 \mathrm{~ms}$ window) to extract the envelope. The resulting waveform was downsampled to match the sampling rate of the eye.

The median $\mathrm{CV}_{2}$ was used to quantify the regularity of neurons. It is similar in principle to the coefficient of variation (CV), but it is less suscep- tible to large variations due to changes in firing rate because it only considers adjacent interspike intervals, and is therefore better suited for analyzing nonstationary firing rates (Holt et al., 1996). $\mathrm{CV}_{2} \mathrm{~S}$ were calculated from interspike intervals (ISIs) as $\mathrm{CV}_{2}=2\left|\mathrm{ISI}_{n+1}-\mathrm{ISI}_{n}\right| /\left(\mathrm{ISI}_{n+1}+\mathrm{ISI}_{n}\right)$.

Preferred directions of units were calculated from spontaneous eye movements in two ways. First, for the directional specificity analysis, we used the perisaccade time histogram approach with 45 or 90 degrees of resolution (see Results, below). After generating peristimulus time histograms (PSTHs), we found the directions that produced the largest perisaccadic increase and decrease in firing rate and considered these the preferred directions for on and off responses, respectively. We then calculated the mean change in firing rate within a $100 \mathrm{~ms}$ window following the first significant change in firing rate for the preferred direction and compared this value with the mean change in firing rate during the same time epoch for each of the three other directions. The first significant change in firing rate was defined as the first time that the firing rate rose above or dropped below 2 SDs of the mean firing rate during a presaccade control period and stayed above or below for at least $100 \mathrm{~ms}$. The time difference between saccade initiation $\left(50^{\circ} / \mathrm{s}\right.$ velocity threshold) and this first significant change in firing rate was taken to be the latency of the neuron. We analyzed on and off responses independently. Because we desired a finer spatial resolution for the preferred direction vectors in the paired Golgi cell-mossy fiber analysis, we used a second approach in which we calculated a saccade vector for each saccade $>2^{\circ}$ in amplitude that resulted in a change in firing rate, scaled each vector by the corresponding change in firing rate, and computed the vector average of all such vectors. The direction of the vector average was taken as the preferred direction of the neuron.

Golgi cell initial changes in IFR were generally well approximated by a rising or falling exponential. However, because of the limited number of data points (i.e., spikes) occurring during this initial phase, an exponential fitting was not always reliable on a saccade-by-saccade basis, so we approximated time constants by measuring the time from the initial change in IFR to the time at which the neuron reached $63 \%$ of its maximal or minimal value. Time constants were measured from the IFR data during spontaneous or visually guided saccades. For each neuron, five saccades were selected in the on or off directions and the time constant of the neuron was taken as the mean of those five measured time constants. When time constants could not be measured in the off direction because the IFR went to zero within a single interspike interval, the time constant was assigned a value of zero (see Fig $2 A$ for example neuron). Because this method of calculating time constants depends on precisely detecting the timing of changes in firing rate on a trial-by-trial basis, time constants could only be measured for the more regular Golgi cells (typically those with median $\mathrm{CV}_{2} \mathrm{~s}<0.2$ ).

Eye-position fields were measured from spontaneous eye-movement data using an algorithm that considered the correspondence of changes in firing rate with starting and ending eye positions of saccades. The motivation behind this approach is exemplified in Figure 5. When the monkey made saccades in the on direction of the neuron, the firing rate increased as long as a portion of the eye movement was encompassed by the eye-position field of the neuron. That is, saccades made into or out of, as well as within, the eye-position field result in changes in firing rate, but saccades made entirely outside of the field produce no change. Considering a series of small sequential saccades in the on direction starting on one extreme of the oculomotor range and ending on the other, the neuron will first start responding when a saccade endpoint crosses into the position field and it will stop responding when a saccade start point crosses out of the position field. Thus, the area between the first saccade endpoint producing a change in firing rate and the last saccade start point producing a change in firing rate defines the position field of a neuron. In practice, this was measured using an interactive program that displayed the instantaneous firing rate and eye position traces around each saccade and allowed the experimenter to indicate the change in instantaneous firing rate following a saccade by marking the initial firing rate immediately preceding the saccade and the maximum firing rate during the postsaccade fixation period. These measured changes in firing rate were then sorted based on either the starting or ending eye position for the saccade (projected along the preferred direction vector of the neuron) 
A

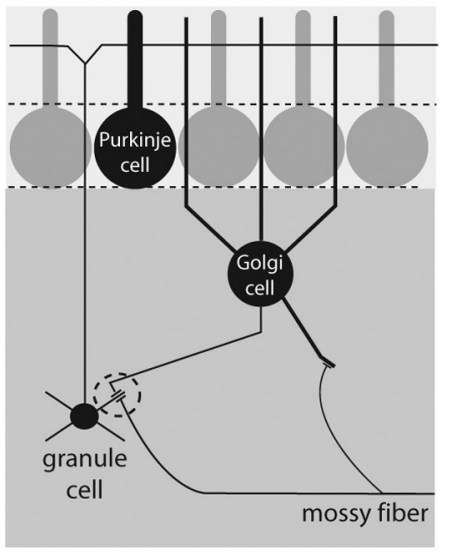

C
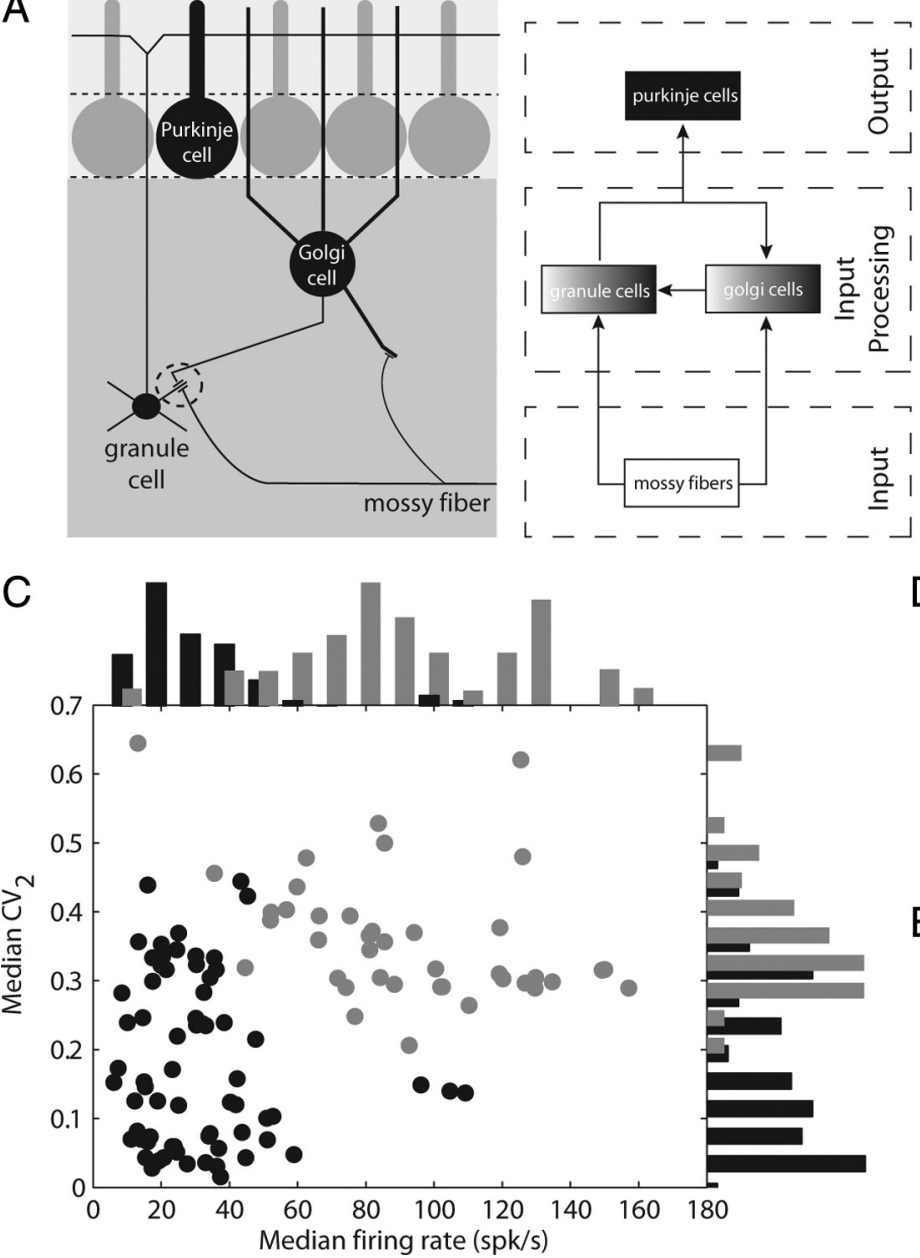

B

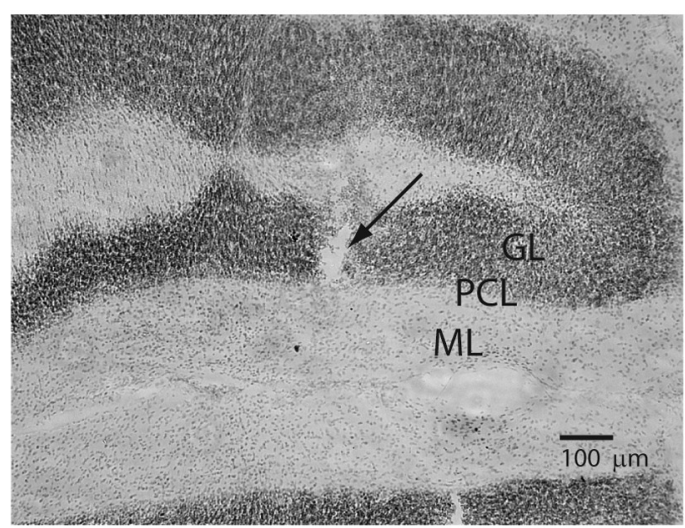

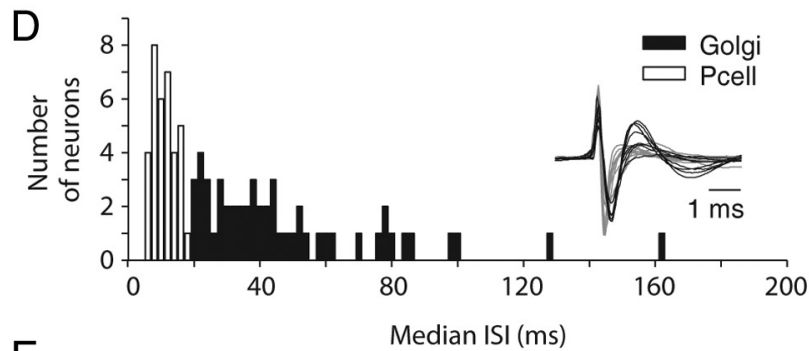

$E$

Median ISI (ms)

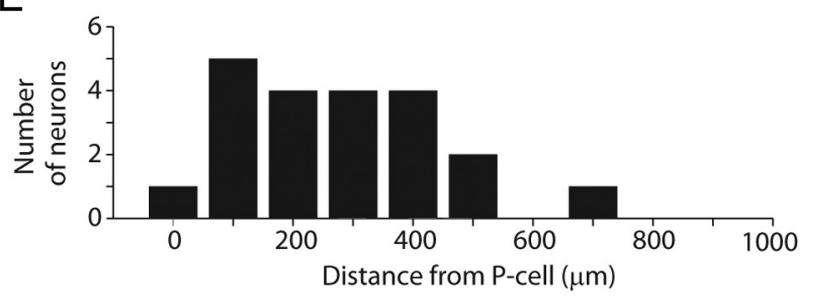

Figure 1. Influence of Golgi cells on cerebellar cortex input layer processing and identification of Golgi cells. A, Schematic diagrams illustrating the position of Golgi cells within the cerebellar cortex circuit. Golgi cells receive mossy fiber inputs via their descending dendrites and soma, and parallel fiber inputs via their ascending dendrites. They strongly inhibit granule cells, which are the main glutamatergic input to Purkinje cells. Because granule cells receive inputs from mossy fibers and in turn provide an input to Golgi cells, this circuit configuration gives Golgi cells both feedforward and feedback control over granule cells. B, Location of electrolytic lesion (arrow) placed after recording a putative Golgi cell in the VPFL. The lesion is located in the granular layer (GL), identified as the dark regions in this nissl stain. The Purkinje cell layer (PCL) and molecular layer (ML) are also indicated for reference. Stimulation parameters: 15 uA cathodal current for $15 \mathrm{~s}$. The location of the Golgi cell recordings was confirmed in two additional lesions. C, Scatter plot of median $\mathrm{CV}_{2}$ and median firing rate for 69 Golgi cells (black) and 42 Purkinje cells (gray) identified based on the presence of complex spikes. The corresponding normalized density histograms are shown on the upper and right edges of the axes. spk/s, Spikes/s. D, Histograms of median interspike intervals for all of the Golgi and Purkinje cells (P-cell) shown in Cand corresponding spike waveforms for a subset of 10 representative neurons from each group. E, Distribution of Golgi cell distances from Purkinje cell layer for 21 neurons for which adequate depth measurements were taken. See also supplemental Figure S1, available at www.jneurosci.org as supplemental material.

and averaged in $2^{\circ}$ bins to generate two curves (see Fig. 5 C). One curve represents the changes in firing rate for all saccade endpoints and the other represents the changes in firing rate for all saccade start points. The intersection of these two curves defines the eye-position field.

\section{Results}

To address the role of Golgi cells in cerebellar processing during oculomotor behaviors, we recorded single-unit activity in the granular layer of the VPFL in alert-behaving squirrel monkeys and used newly established criteria to identify the characteristic activity of Golgi cells in vivo. The VPFL granular layer was recognized based on the presence of eye movement-related hashing activity, large unitary discharges and presumed mossy fiber discharges, and the absence of complex spikes (Lisberger and Fuchs, 1978b; Miles et al., 1980; Blazquez et al., 2003). In the granular layer, we commonly encountered two kinds of single unit activity. The first were units with narrow spikes $(\sim 100 \mu$ s peak to trough time), which usually discharged with a burst/burst-tonic eye movement-related response, a vestibular-related response, or a combination of eye- and vestibular-related responses. These units often had short tracking distances, matched the character of the background hashing, and were difficult to maintain in isolation for extended periods of recording. Therefore, these units were presumed to be mossy fibers (Lisberger and Fuchs, 1978b; Miles et al., 1980; Noda, 1986). The second units were usually tonically active, had broader spikes $(>200 \mu$ s peak to trough time) and lower median firing rates, and isolation could often be maintained for $>10 \mathrm{~min}$ and sometimes up to $1 \mathrm{~h}$. This second type of unit was almost always heard in the background when passing through the granular layer but was not always possible to isolate. These units were determined to be Golgi cells based on the spike profiles and interspike interval distributions of morphologically identified Golgi cells published by others (Vos et al., 1999; Simpson et al., 2005; Holtzman et al., 2006; Prsa et al., 2009) and the absence of complex spike responses characteristic of Purkinje cells (Thach, 1968). Figure $1 B$ shows the location of an electrolytic lesion made after recording one of 
these presumed Golgi cells, confirming its position in the granular layer.

We recorded a total of 69 putative Golgi and 40 Purkinje cells in four squirrel monkeys $(083,087,066$, and 078). We quantified the spike patterns of the Golgi and Purkinje cells using their median firing rate and median $\mathrm{CV}_{2}$. Holtzman et al. (2006) have previously shown that the median firing rate is the most useful known criterion for identifying Golgi cells. We found that this was true among our population of neurons as well. In addition, we found that Golgi cells exhibited a high variability in firing rate regularity, which we quantified using the $\mathrm{CV}_{2}$ metric (see Materials and Methods) (Holt et al., 1996; Shin et al., 2007). Figure $1 C$ shows a scatter plot of median $\mathrm{CV}_{2}$ values versus median firing rates for all recorded Purkinje and presumed Golgi cells. Although Golgi cells were capable of reaching firing rates as high as $100 \mathrm{~Hz}, 87 \%(n=60)$ of them had median firing rates $<50$ spikes/s, whereas 93\% $(n=37)$ of Purkinje cells had median firing rates above this value. The median $\mathrm{CV}_{2}$ metric also allows separation of Purkinje and Golgi cells, but with more overlap between distributions than the median firing rate. The majority of Golgi cells $(61 \%, n=42)$ had $\mathrm{CV}_{2}$ s lower than 0.2 , indicating a high regularity absent in the Purkinje cell population. We have included in our population of Golgi cells the three neurons with median firing rates $>80$ spikes/s because these neurons met our criteria for identification, although they responded differently during our tasks than the rest of the population and we suspect they may be unipolar brush cells (see supplemental materials, available at www.jneurosci.org). For comparison with Figure 1 of Holtzman and colleagues (2006), Figure $1 D$ shows the median ISI distribution of the neurons displayed in Figure 1C. Despite the difference in species (monkey vs rat) and behavioral state (awake vs anesthetized), our Purkinje and Golgi cell ISI distributions are qualitatively similar to those of Holtzman and colleagues, albeit with ours shifted toward shorter median ISIs (see supplemental materials and supplemental Fig. S1, available at www.jneurosci.org, for a more in depth comparison). We now describe the characteristic responses of this population of Golgi cells in the context of vestibulo-oculomotor behaviors known to involve the VPFL.

\section{Golgi cells in the VPFL exclusively code eye movements during visuo-oculomotor and vestibulo-oculomotor behaviors}

The primate VPFL receives mossy fiber input from diverse sources that convey vestibular, visuomotor, and eye movement information (Langer et al., 1985). Indeed, single Purkinje cells in the VPFL, the output neuron of the structure, also contain signals reflecting each of these pathways (Lisberger and Fuchs, 1978a; Miles et al., 1980; Noda and Warabi, 1987). Because, like Purkinje cells, the broad ascending dendritic trees of Golgi cells also receive inputs from the parallel fiber system, which is thought to convey converging information from different modalities (eye movement, vestibular, and visual), we hypothesized that single Golgi cells would respond to all major inputs to the flocculus in a similar manner as Purkinje cells. We recorded Golgi cells while the monkeys performed tasks that isolate the signals of each modality, namely pursuit, VORS, and F-WFS (see Materials and Methods). We recorded a total of 48 Golgi cells during the pursuit-only task, 23 Golgi cells during the pursuit and VORS tasks, and 7 Golgi cells during all three tasks. Surprisingly, in contrast to Purkinje cells, Golgi cells responded to eye movements but not to head movements or visual motion. Figure 2, $A-D$, presents the responses of a representative Golgi cell during spontaneous saccades, pursuit, VORS, and F-WFS. This Golgi cell had a median $\mathrm{CV}_{2}$ of 0.09 and median firing rate of 38 spikes/s. The neuron modulated to changes in eye position during spontaneous saccades (Fig. 2A) and approximately in phase with changes in eye position during pursuit (Fig. $2 B$ ), but was unmodulated during VORS and F-WFS, indicating a lack of a vestibular or visual motion response. Figure 2, $E-G$, show the average Golgi cell firing rate over at least five cycles plotted against eye position, head velocity, or visual motion (retinal slip) velocity during pursuit, VORS, or F-WFS, respectively. A regression fit to each curve reveals that the changes in eye movement during pursuit contribute the most to the firing-rate modulation (slope $=2.3,0.06$, and -0.04 , respectively). This dominance of eye-movement responses was seen across the population of Golgi cells tested (mean ratio of pursuit/VORS slopes, 19.5; mean ratio of pursuit/F-WFS slopes, 7.2) (Fig. 2H,I). Note the strong clustering of data points along the ordinate axis in Figure 2, $H$ and $I$, indicating a lack of vestibular or visual motion responses by the population of Golgi cells. This exclusive coding of eye movements was also present during behaviors that recruit the different pathways in combination, such as head rotation during fixation of an earth-fixed target (VOR with target) (see supplemental Fig. S2, available at www.jneurosci.org as supplemental material). Golgi cell modulation during the VOR-with-target task was identical to the modulation during pursuit in the absence of head movement, which is consistent with an exclusive coding of the eye movement and indicates that Golgi cells in the VPFL respond to eye movements regardless of whether they are driven by the pursuit or vestibular system.

Similarly to many of the VPFL mossy fibers conveying eye movement signals (Miles et al., 1980), Golgi cells also responded to eye movements during saccades. Therefore, we used spontaneous (free viewing condition; see Materials and Methods) and visually guided saccades to more fully quantify the properties of the eye movement coding by Golgi cells. Figure 3 shows the diversity of Golgi cell responses during spontaneous eye movements for four different representative neurons (Fig. 3A-D) and the population as a whole (Fig. $3 E-F$ ). The most common type of response seen in Golgi cells during spontaneous eye movements was a sudden decrease (Fig. $3 A$ ) and, in many cases, a complete pause (Fig. $3 B$ ) in the firing rate following a saccade in a particular direction, which we refer to as the off direction (54/69; 78\%). In some cases, the pause was preceded by an initial burst, but this was not always present, even for different saccades within the same neuron. Following a pause, the Golgi cell firing rate gradually recovered toward a tonic level. This recovery was usually cut short by a response to the next spontaneous saccade. In some neurons, we were able to measure the time course of the recovery more fully by having the monkey make saccades to laser targets and fixate for more extended periods; the recovery time constants ranged from 110 to $820 \mathrm{~ms}$ (mean, $438 \pm 361 \mathrm{~ms} ; n=21$ ).

Additionally, 71\% (49/69) of Golgi cells showed an increase in firing rate with changes in eye position, which we refer to as an on response, that was noticeably distinct from a rebound following an off response (Fig. 3C). A subset of Golgi cells displayed rapid bursts for saccades in the on direction, similar to typical mossy fiber burst-tonic responses $(n=12 ; 25 \%)$ (Fig. $3 D)$, whereas the majority experienced more gradual increases in firing rate following a saccade in the on direction $(n=37 ; 75 \%)$. These gradual increases in firing rate are not seen in VPFL mossy fiber population (Lisberger and Fuchs, 1978b; Miles et al., 1980) and could reflect a low-pass filtering of eye movement signals by the Golgi cells. The burstiness of the population of Golgi cells is quantified 
in Figure $3 E$ as a burst-tonic ratio, calculated as the ratio of the maximum firing rate within the first $50 \mathrm{~ms}$ following response onset and the maximum firing rate between 100 and $150 \mathrm{~ms}$ from response onset. Ratios above 1 would indicate that the burst accounts for the dominant change in firing rate of the neuron. Contrary to this, the majority of Golgi cells had burst-tonic ratios of $<1$ (median burst-tonic ratio, 0.49), indicating that the population of Golgi cells had gradual excitatory responses compared with bursttonic mossy fibers. These responses were more gradual than the off-direction responses, with time constants often greater than the duration of the saccade (mean offdirection time constant, $61 \pm 62 \mathrm{~ms}$; mean on-direction time constant, $124 \pm 107 \mathrm{~ms}$; $n=34 ; p<0.005$, Mann-Whitney $U$ test) (Fig. 3F). Similarly to off-direction responses, following the initial on response, Golgi cell firing rates decayed down to a tonic rate. The time constants of this decay were often longer than the squirrel monkeys were capable of fixating on a laser target, so we were unable to calculate time constants representative of the population. However, others have found the value of this time constant in the macaque to be $\sim 6.5 \mathrm{~s}$ on average for a similar population of presumed Golgi cells (Miles et al., 1980).

Contrary to the differences in initial time constants, Golgi cells had similar latencies to the first significant change in firing rate ( $>2$ SDs above or below mean presaccadic firing rate) for on and off responses, as measured during spontaneous saccades, and the responses tended to lag the eye movement (on, $36.4 \pm 65.3 \mathrm{~ms}$; off, $29.9 \pm 54.6 \mathrm{~ms}$; mean $\pm \mathrm{SD} ; p=0.88$, Mann-Whitney $U$ test). This suggests that a similarly timed input is responsible for both the on and off responses of the Golgi cells but that the temporal dynamics of the input, or the Golgi cell response to the input, is different for on and off responses.

Because others have reported that Golgi cells in the oculomotor vermis (OMV) have broad directional tuning for saccades (Prsa et al., 2009) and that Golgi cells in crus I/II have large cutaneous receptive fields (Vos et al., 1999; Holtzman et al., 2006), we sought to determine how broadly tuned Golgi cells in the VPFL are for eye movements. To address this question, we analyzed the tuning of on and off responses during spontaneous eye movements. To ensure that we had a sufficient number of saccades to produce reliable averages for a large number of cells, we segmented the oculomotor space into four $90^{\circ}$ zones centered on each of the cardinal directions and assigned each saccade to a zone based on the direction of the saccade vector. We then computed PSTHs by binning together Golgi cell spikes, aligned on saccade onset, for all saccades falling within a zone. This gave us four separate PSTHs, each representing the perisaccadic activity of the Golgi cell for saccade directions falling within $\pm 45^{\circ}$ of each of the cardinal directions (see
Materials and Methods) (Fig. 4A). Figure 4, $B$ and $C$, presents the results of this analysis for 49 neurons with significant on responses and 54 neurons with significant off responses. The numbers along the abscissa indicate the cardinal directions with the highest, second highest, third highest, and lowest response for each neuron, and the ordinate axis indicates the response magnitude for that direction, normalized by the response in the preferred cardinal direction. Values of 1 for every direction would indicate that the neuron has an omnidirectional response, and values of 1 for only the preferred direction (direction 1) would indicate a narrowly tuned neuron to that cardinal direction. In support of the latter, $65 \%$ of neurons $(32 / 49)$ showed an on response for the second-most responsive direction that was $<50 \%$ of the maximal on response (in the preferred direction), and 96\% (47/49) showed a less-than-half maximal response for the third-most responsive direction. Likewise, $70 \%$ of 
A

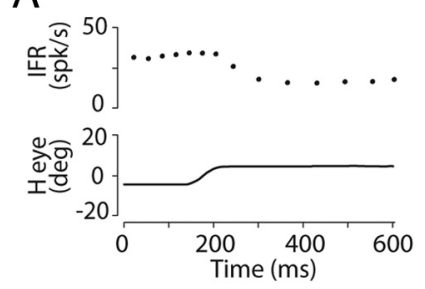

C
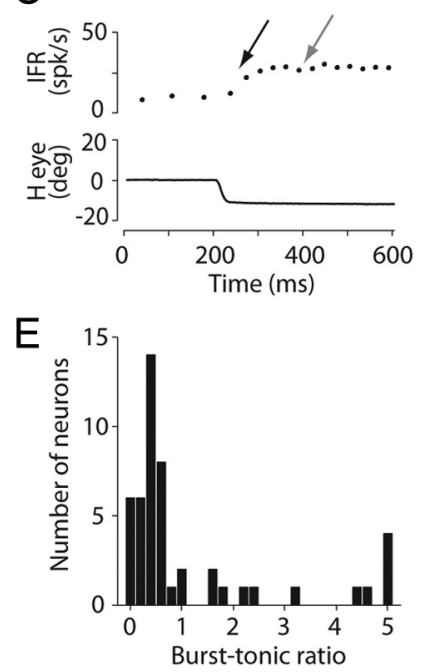

$\mathrm{B}$

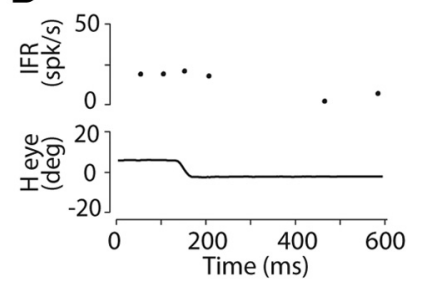

D

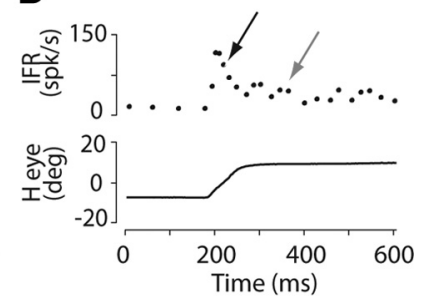

$\mathrm{F}$

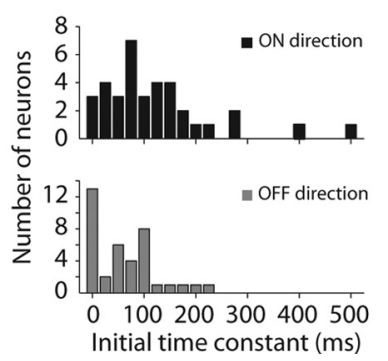

Figure 3. Temporal properties of Golgi cell responses. $A-D$, Representative off $(\boldsymbol{A}, \boldsymbol{B})$ and on $(\boldsymbol{C}, \boldsymbol{D})$ responses of four different Golgi cells during saccades. Top, IFR; bottom, horizontal eye position (Heye). $\boldsymbol{E}$, Distribution of burst-tonic ratios for 49 Golgi cells with significant on responses. Arrows in $\boldsymbol{C}$ and $\boldsymbol{D}$ indicate regions used to calculate burst-tonic ratios (see text). $\boldsymbol{F}$, Distributions of on (top) and off (bottom) initial time constants for 34 Golgi cells. spk, Spike.

neurons (38/54) showed an off response for the second-most responsive direction that was $<50 \%$ of the maximal off response, and $93 \%(50 / 54)$ showed a less-than-half maximal response for the third-most responsive direction. Thus, our VPFL Golgi cells were more narrowly tuned than the oculomotor vermis Golgi cells of Prsa and colleagues (2009), as a majority of their Golgi cells would be expected to have greater-than-half maximal responses for at least three zones under our analysis method. The narrow directional tuning of our Golgi cells was further supported by analysis of vertical and horizontal pursuit data obtained from 29 Golgi cells (supplemental Fig. S3, available at www.jneurosci.org as supplemental material). Seventy-six percent of the neurons $(n=22)$ modulated at least twice as much during pursuit in the preferred plane compared with the orthogonal plane, with a median ratio of 5.5 (slope preferred/slope orthogonal). This result stands in contrast to Golgi cell responses reported in the oculomotor vermis and crus I/II, and may reveal a functional difference between the ventral paraflocculus and other cerebellar areas.

The preferred directions calculated during spontaneous saccades were uniformly distributed among the four zones for both on $(n=14,11,15$, and 9; ipsilateral, contralateral, up, and down, respectively) and off responses ( $n=13,11,13$, and 17; ipsilateral, contralateral, up, and down, respectively). However, not all neurons were tuned for the cardinal directions. The fact that many cells did not respond strongly in the third-most responsive direction indicates that many of the cells were tuned for noncardinal directions. We confirmed this by generating eight-zone PSTHs for 24 cells with a sufficient number of spontaneous saccades and found that $92 \%$ of cells had greater-than-half maximal responses

for three or fewer $45^{\circ}$ zones, and 58\% of the cells had greaterthan-half maximal responses for exactly three zones. This argues both that Golgi cells are narrowly tuned, and that a sizeable proportion of them have noncardinal preferred directions. Indeed, when preferred directions were approximated from the fourzone PSTHs for all Golgi cells by taking the vector average of responses to the first and second maximal directions, $46 \%$ of the neurons had preferred on directions and $51 \%$ had preferred off directions $>15^{\circ}$ from a cardinal direction. Furthermore, on- and off-directional preferences tended to be counterweighted. In $85 \%$ (34/40) of the neurons that had both significant on and off responses, the preferred directions for the on and off responses pointed in opposite directions (Fig. $4 A$ ).

\section{Golgi cell responses have eye-position fields}

The Golgi cell shown in Figure 2, $A-G$, had an apparent saturation in firing rate during both saccades and pursuit. We determined that this saturation was not due to intrinsic properties of the neuron such as spike refractoriness, but was instead related to an eye-position threshold. Figure 5 presents this phenomenon more fully for a representative neuron. When the monkey pursued a sinusoidally moving target centered $5^{\circ}$ to the left, the firing rate of the neuron modulated smoothly with changes in eye position (Fig. 5A, left). However, when the monkey pursued a moving target centered $5^{\circ}$ to the right, the neuron was unmodulated (Fig. 5A, right). We call the active eye-position range of a Golgi cell the eye-position field of the neuron and we differentiate between eye-position fields for on and off responses. Note that there is a difference in baseline firing rate between the two conditions. This is the result of accumulated firing rate increases for eye movements within the eye-position field of the neuron due to the long time constant of decay. The eye-position field of this same Golgi cell can also be seen during the spontaneous eye movements produced during the free viewing condition (Fig. 5B), indicating that the position fields are present during both pursuit and saccades. Note in Figure $5 B$ that a rightward (positive) saccade starting $\sim-7^{\circ}$ resulted in a corresponding change in firing rate of the neuron (black arrow), whereas a rightward saccade of a similar amplitude starting $\sim 2^{\circ}$ had no effect on the firing rate (gray arrow). By applying an algorithm that looks for changes in firing rate resulting from saccades with many different start and end points covering the entire oculomotor range of the monkey (see Materials and Methods), we determined that this Golgi cell had an eye-position field between -18 and $2^{\circ}$ for increases in firing rate (on direction) (Fig. $5 C$, left). That is, for rightward (on direction) saccades, this neuron was not responsive to saccades starting and ending at $<-18^{\circ}$ or $>2^{\circ}$, but it was responsive to saccades starting or ending within the range defined by these two boundaries. Likewise, for leftward saccades (off direction) (Fig. $5 C$, right), this neuron was not responsive for saccades made outside a range of -14 to $5^{\circ}$. Figure $6, A$ and $B$, show the distribution of on eye-position fields for 19 Golgi cells and off eyeposition fields for 20 Golgi cells for which we had sufficient data to apply our algorithm. We confined our analysis of spontaneous eye movements to only those Golgi cells with median $\mathrm{CV}_{2} \mathrm{~s}<0.2$ because the regularity of the spike times allowed us to detect changes in instantaneous firing rate on a saccade-by-saccade basis without relying on averaging. Using this approach, we found that individual Golgi cells have eye-position fields distributed throughout the squirrel monkey oculomotor range, with the population blanketing the entire range and being centered approximately around the center of gaze, but with individual Golgi cell fields only occupying a portion of the total range. The mean 
eye position field size across the population was $15.7 \pm 7.4^{\circ}$ in the on direction and $17.9 \pm 8.0^{\circ}$ in the off direction, with a strong correlation between the size of the on and off fields on a per neuron basis for the 17 neurons in which we were able to calculate both the on and off position fields (Pearson correlation coefficient, $0.81 ; p \ll 0.05$ ) (Fig. 6C).

In addition, there was a high degree of overlap between the on and off position fields for a given neuron, such that the eye position at which a Golgi cell first began to respond with a decrease in firing rate in the off direction was usually within a few degrees of the eye position at which a Golgi cell stopped responding in the on direction. Figure $6 \mathrm{D}$ shows a plot of the upper response field border for the off direction versus the upper response field border for the on direction for the 17 neurons with sufficient data to measure both the on and off position fields. Most points align along the unity line, indicating a correspondence between these two borders for most neurons. This suggests that a similarly tuned input to the Golgi cells accounts for both the on and off responses of the neurons. We address the nature of this input in the next section.

\section{Golgi cell relationship with mossy fiber input}

As depicted in the cerebellar cortex circuit schematic in Figure 1A, Golgi cells receive glutamatergic input via two separate pathways: a direct mossy fiber input to the Golgi cell soma and descending dendrites and a feedback input via the parallel fibers (Eccles et al., 1967; Chan-Palay and Palay, 1971). The mossy fiber synapses are known to be strong (Kanichay and Silver, 2008) and the parallel fiber synapses relatively weak (Dieudonne, 1998), so we wondered to what extent the mossy fiber input could explain the Golgi cell firing-rate responses described above. In nine recording sessions, we were able to record simultaneously from a Golgi cell and either an isolated mossy fiber single unit $(n=5)$ or multiunit hashing activity made up of one or a few single units that could not be fully isolated $(n=4)$. The single unit activity was thought to represent mossy fiber terminals rather than granule or other cell types because the spike profile and response type matched the characteristics previously described for mossy fibers (Lisberger and Fuchs, 1978b; Miles et al., 1980; Noda, 1986) and because the impedance of our electrodes was probably too low to reliably isolate small, densely packed neurons such as granule cells. The
A
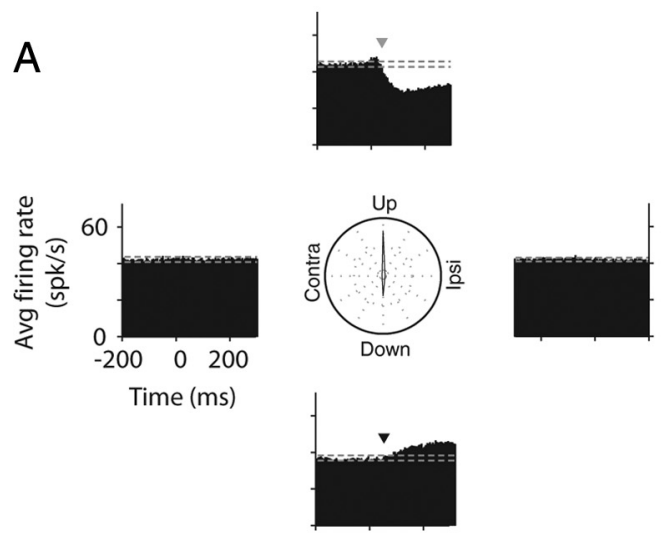

B
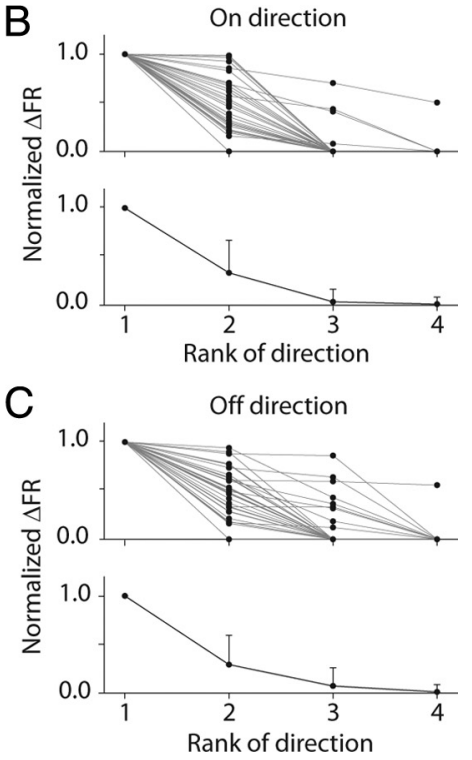

Figure 4. Directional tuning of Golgi cells. $A$, PSTHs of a Golgi cell response to spontaneous saccades within $\pm 45^{\circ}$ of each cardinal direction. Gray dotted lines indicate 2 SDs above and below the control firing rate, which was used to calculate the first significant increase or decrease in firing rate, respectively. Bin size is $5 \mathrm{~ms}$. Center plot indicates absolute depth of modulation for each of the four directions. Ipsi, Ipsilateral; contra, contralateral. The distance from the center of the circle to the perimeter equals 20 spikes/s (spk/s). $\boldsymbol{B}, \boldsymbol{C}$, Number of directions with on $(\boldsymbol{B})$ or off $(\boldsymbol{C})$ responses. Each line in the top panel represents a single neuron and the dots indicate the normalized change in firing rate $(\Delta F R)$ for saccades in a particular cardinal direction zone. The directions were ranked by response amplitude such that the numbers along the abscissa indicate the most- to least-responsive directions, with direction 1 being the preferred direction. For both $\boldsymbol{B}$ and $\boldsymbol{C}$, the bottom panel shows the mean and SD for all neurons. See also supplemental Figure S3, available at www.jneurosci.org as supplemental material.
A
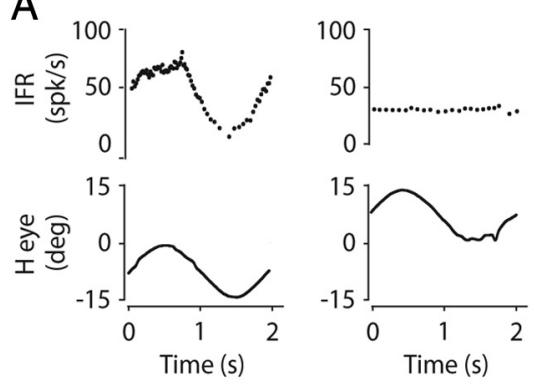

C

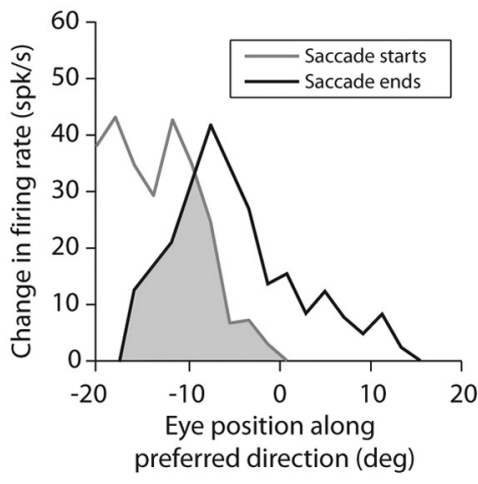

B
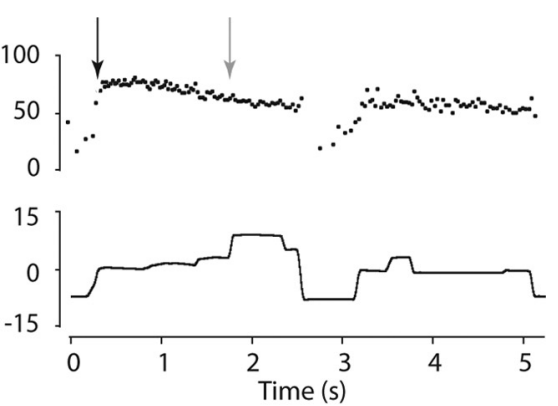

Figure 5. Eye position fields of a single Golgi cell. $\boldsymbol{A}$, Response of Golgi cell during pursuit of a target to the left (left) or right (right) of the center of gaze. Top, IFR; bottom, horizontal eye position (H eye). $\boldsymbol{B}$, Response of same Golgi cell during spontaneous eye movements. Arrows indicate on response (black) or absence of on response (gray) for two saccades of similar amplitude, but with different starting positions. C, Calculated on (left) and off (right) eye position fields for the same neuron. For both panels, the gray curve indicates changes in firing rate during saccades versus saccade start points and the black curve indicates changes in firing rate during saccades versus saccade end points. The shaded region is the intersection of these two curves, which defines the eye position field of the neuron (see Materials and Methods). 
A

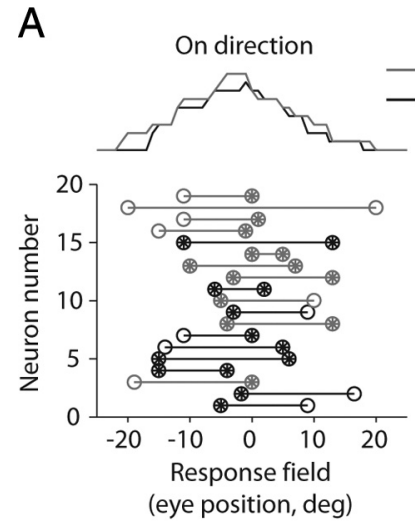

\section{B}
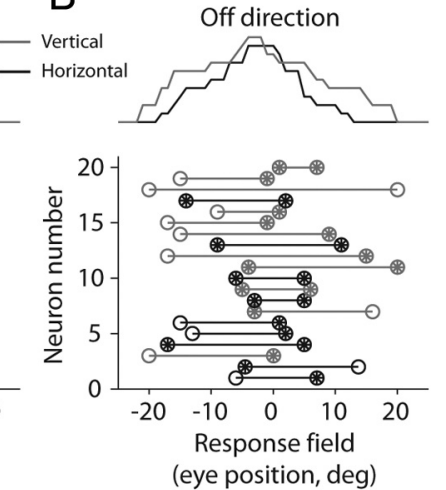

C

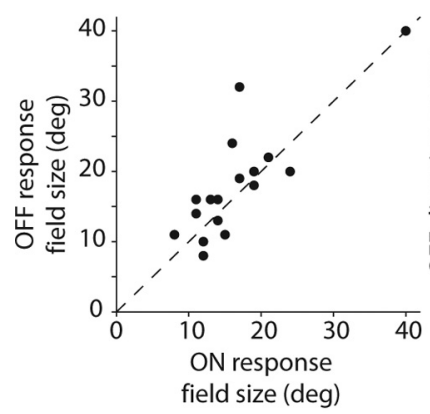

D

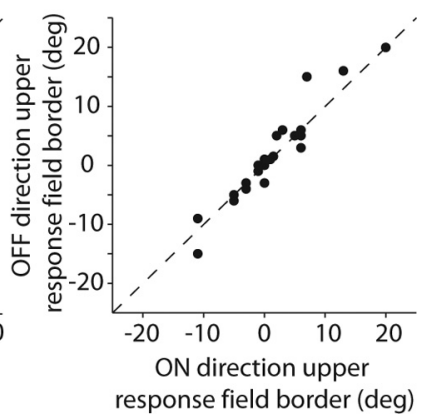

Figure 6. Eye-position fields for the population of Golgi cells. $A, B$, Extent of eye-position response fields for 19 Golgi cells in the on direction $(\boldsymbol{A})$ and $20 \mathrm{Golgi}$ cells in the off direction $(\boldsymbol{B})$. Circles indicate borders of position fields. Open circles correspond to estimates of borders that were not clear due to an insufficient number of saccades beyond that position. Gray, Vertical eye-movement cells; black, horizontal eye-movement cells. Positive numbers are up and ipsilateral. Top histograms indicate distributions of eye-position field extents using $1^{\circ}$ bins and summing the bins across all neurons. $C$, Relationship between eye-position response field sizes for on and off directions in 17 Golgi cells. Diagonal line indicates equal sizes. D, Relationship between the eye position at which a Golgi cell first starts to respond in the off direction (upper off border) and stops responding in the on direction (upper on border) for the same $17 \mathrm{Golgi}$ cells. Points falling along the diagonal line indicate that the on and off upper eye position field borders are the same.

multiunit hashing was also thought to reflect the activity of one or a few mossy fiber terminals because the response type and directional tuning of the hashing tended to match that of mossy fiber single units recorded nearby.

The results of these nine simultaneous Golgi cell-mossy fiber recording sessions are presented in Figure 7. Figure 7A shows the raw extracellular recording trace and the instantaneous firing rates for the sorted mossy fiber and Golgi cell of one such session. Surprisingly, given the glutamatergic nature of the mossy fiberGolgi cell synapse, the two units appear to have an antiphasic relationship, whereby an increase in firing rate of one unit is accompanied by a decrease in firing rate of the other unit. This relationship was confirmed by calculating a peristimulus time histogram of Golgi cell spikes aligned with respect to either the mossy fiber burst (Fig. 7B, top) or pause (Fig. 7B, bottom). A clear dip in the Golgi cell firing rate is observed following mossy fiber bursts and a clear rise in the Golgi cell firing rate is observed following mossy fiber pauses. Note that the Golgi cell off responses evolved faster than the on responses (initial time constants), as also seen in the population of Golgi cells (cf. Fig. 3F). A potential explanation for this phenomenon becomes clear from examining the simultaneous mossy fiber and Golgi cell responses. That is, the fast Golgi cell off responses coincide with mossy fiber bursts, which are a rapid and strong stimulus, whereas the slower
Golgi cell on responses coincide with cessations of mossy fiber tonic activity, a relatively weaker stimulus. This suggests that Golgi cell time constants are a reflection of both the intrinsic membrane properties of the neurons (Forti et al., 2006) and the level of activity of the mossy fibers that innervate them.

The apparent antiphasic relationship was further explored by calculating the preferred direction vectors for both the mossy fiber and Golgi cell, which were found to point in opposite directions for this pair and for the population of paired recordings as a whole (Fig. 7C). The relative latencies from saccade initiation of mossy fiber bursts and Golgi cell pauses and vice versa suggest that both the mossy fiber increases and decreases in firing rate precede the corresponding changes in Golgi cell firing rate (Fig. $7 D$ ). Finally, for the nine pairs tested, there was a strong correlation between the eye-position activation threshold for a mossy fiber and the off-direction upper eye-position field boundary of the corresponding Golgi cell (Pearson correlation coefficient, $0.91 ; p \ll 0.05)$.

To get a better picture of how widespread the antiphasic mossy fiber-Golgi cell responses were, we analyzed an additional 10 Golgi cells for which mossy fibers had been isolated in the same folium during the same recording session, but were not recorded simultaneously. Of these, nine Golgi cells had pauses in firing rate for saccades in the on direction of a nearby mossy fiber, suggesting that the mossy fiber may have been contributing to the pause. The remaining Golgi cell had the same on direction as a mossy fiber recorded nearby. It was not clear how the mossy fiber terminals themselves were distributed in terms of preferred directions. On the one hand, multiunit activity was often narrowly tuned for eye position $(n=11 / 13)$, suggesting some response homogeneity of mossy fibers in the volume of space picked up by our electrodes; on the other hand, mossy fibers with different directional tunings were routinely recorded within the same folium on a single electrode track $(n=7 / 8)$, often $<100$ micrometers apart. It is interesting to note that on those sessions where multiple mossy fibers were recorded near a Golgi cell, the Golgi cell pause was only explained by the directional preference of one of the mossy fibers $(n=3)$.

Together, these data support the hypothesis that the mossy fiber inputs contribute to the Golgi cell's pause in firing rate and suggest that Golgi cells may only sample a subset of the available mossy fiber and parallel fiber activity.

\section{Discussion}

Golgi cells exert strong inhibitory control over granule cells, placing them in a strategic position to control the information entering the cerebellar cortex (Eccles et al., 1967). We quantified for the first time the response properties of VPFL Golgi cells in the alert monkey, revealing four primary characteristics that will help us to better understand the role of Golgi cells in cerebellar cortical processing. First, VPFL Golgi cell firing rates are predominantly driven by ongoing eye movements. Second, VPFL Golgi cell firing rates change on at least two time scales, an initial increase or decrease in firing rate with mean time constants of tens to hundreds of milliseconds and a longer decay or rebound in firing rate with time constants of hundreds of milliseconds to tens of seconds. Third, VPFL Golgi cells have eye-position fields covering only a portion of the entire oculomotor range of the monkey. Fourth, VPFL Golgi cell responses have an antiphasic relationship with nearby mossy fibers. We discuss these properties in more depth below and offer our hypotheses about their functional significance in the cerebellar cortical circuit. 
Eye-movement coding by VPFL

Golgi cells

The Golgi cells we recorded appeared to be exclusively driven by eye movementrelated inputs and were unmodulated by vestibular or visual signals. This specificity of input is surprising not only because the large ascending dendritic fields of the Golgi cells suggest that they receive a broad convergence of diverse inputs, but also because vestibular, visual, and oculomotor signals are often already combined at the level of many VPFL projecting neurons (Mustari et al., 1988; Nakamagoe et al., 2000). The fact that VPFL Golgi cells respond specifically to the eye movement inputs suggests a highly specific connectivity in the input layer of the cerebellar cortex that, to our knowledge, has not been previously reported. The eyemovement inputs are likely derived from brainstem areas such as the nucleus of the prepositus hypoglossi and paramedian tract, which contain burst-tonic eye movement-related signals thought to convey an efference copy of oculomotor commands (Green et al., 2007). Within the computational framework of cerebellar cortex function in motor control, this exclusive coding of an efference copy signal suggests that Golgi cells, through their regulation of granular layer throughput, may play a critical role in the construction of internal models of the oculomotor system (e.g., forward models).

In contrast to their burst-tonic mossy fiber inputs, VPFL Golgi cells have relatively slow time dynamics (Fig. $3 E, F$ ), with firingrate rise times in the on direction often outlasting the duration of the saccade. The off-direction responses tend to occur more rapidly (on average, twice as fast as ondirection responses), with a complete pause in firing often occurring within a single interval of the instantaneous firing rate (Figs. $2 A, 3 B$ ), but with some neurons having offdirection time constants on the order of hundreds of milliseconds. In addition, VPFL Golgi cells have a second, longer time constant for recovery from off responses and decay from on responses. These longer time constants were reported by Miles and colleagues (1980), but the shorter initial ones were not. Together, the varied time constants give these Golgi cells the properties of a bandpass filter on behaviorally relevant time scales. Specifically, the majority of VPFL Golgi cells reject high-frequency inputs such as bursts (Fig. $3 F$ ) and low-frequency inputs such as tonic eye-position signals during steady fixations. Because Golgi cells strongly inhibit granule cells, this passband would be inverted at the level of granule cells, allowing only relatively high- or low-frequency mossy fiber inputs to readily pass the input stage of the cerebellar cortex. This is consistent with previously reported observations that granule cells exhibit short, well timed bursts in response to stimulation (Chadderton et al., 2004). Such a scheme could provide a mechanism for granule cells to compute the time derivative of mossy fiber
$\mathrm{B}$

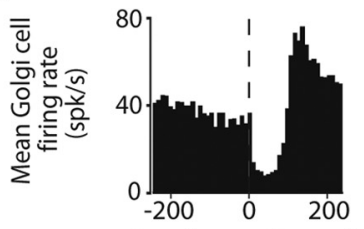

Lag from $\mathrm{mf}$ burst (ms)

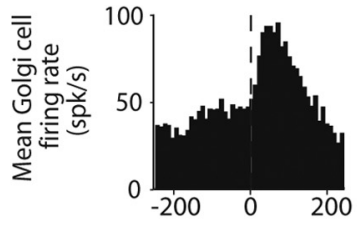

Lag from mf pause (ms)

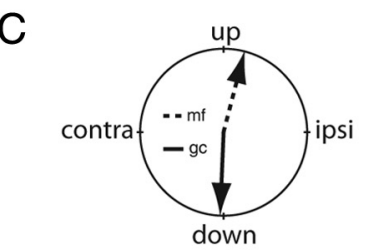

Directional preference (deg)
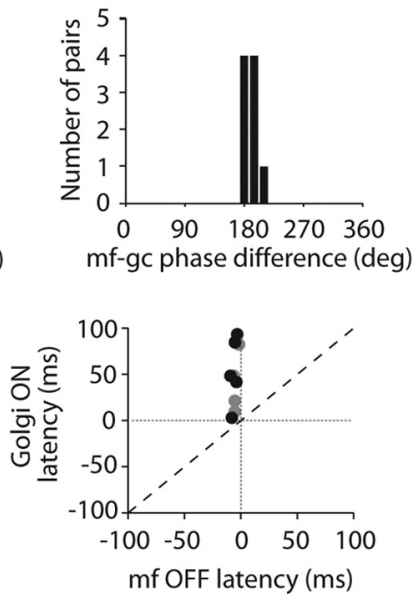

Figure 7. Relationship between mossy fiber ( $\mathrm{mf}$ ) and Golgi cells $(\mathrm{gc})$ simultaneously recorded during spontaneous eye movements. $A$, Raw trace from extracellular recording of a mossy fiber-Golgi cell pair on the same electrode (top) and corresponding IFR for the mossy fiber (middle) and Golgi cell (bottom). An upward saccade occurred $\sim 90 \mathrm{~ms}$ and a downward saccade occurred (300 $\mathrm{ms}$, producing a burst and then a pause in the mossy fiber firing rate. Note that the Golgi cell appears to be negatively burst (top) or pause (bottom). C. The negative coupling between the same mossy fiber-Golgi cell pair is also expressed as opposite directional preferences for on responses (left). This is true for the entire population of nine pairs (right). $\boldsymbol{D}$, Relationship between Golgi cell off response latencies and mossy fiber on latencies (left), and Golgi cell on response latencies and mossy fiber off latencies (right) for all nine mossy fiber-Golgi cell pairs. Mossy fiber single units are shown as black dots and multiunit hashing is shown as gray dots. Dalling above the diagonal line indicate that the mossy fiber responds before the Golgi cell. The cluster of three dots D, right, top) correspond to Golgi cells with on latencies that fall outside the range displayed in the plot. These latencies are 114, 13, and 157 ms. spk, Spike; contra, contralateral; ipsi, ipsilateral.

inputs, thus giving Purkinje cells their observed phase advanced eye signal relative to the mossy fibers (Lisberger and Fuchs, 1978a). On the other hand, the long time constant could be used in computations involving events occurring on longer time scales, such as learning, because the time course of the decay holds a de facto short-term memory of past eye positions.

Miles and colleagues (1980) previously noted that firing rates of putative Golgi cells in the flocculus often saturate at a particular eye position, usually near the center of gaze. We extend this finding by showing that the eye position-related saturations are often bounded on two sides, forming an eye-position field in which each neuron is active. These eye-position fields do not appear to be limited to a particular hemifield, as Miles and colleagues (1980) suggested, but rather can span both hemifields (Fig. 5). Furthermore, we show that the eye position at which a given Golgi cell firing rate saturates in the on direction corre- 
sponds, within a few degrees, with the eye position at which the same neuron begins responding in the off direction (Fig. 6). Our simultaneous recordings of mossy fibers and Golgi cells suggest a plausible mechanism for generating the eye position fields in which a given Golgi cell's eye-position field is determined by the activation threshold and response range of the mossy fiber(s) providing its dominant input(s). Since Golgi cells in the VPFL appear to only reflect the activity of the efference copy pathway and the relationship between the mossy fibers and Golgi cells is antiphasic, the Golgi cell activity in essence provides a negative image, with an additional temporal transformation, of the motor command being sent to the extraocular muscles. The axonal fields of individual Golgi cells appear to be mostly nonoverlapping (Eccles et al., 1967), suggesting that as little as a single Golgi cell will provide the main inhibitory control over a cluster of granule cells. Consequently, individual granule cells may only "see" one eye-position field. Functionally, this arrangement could create modules of granule cells defined within a volume of space, with each module governed by, at most, a few Golgi cells and each reflecting a different state- and time-filtered signal that can be combined by downstream neurons such as Purkinje cells.

It is not clear how much of these results can be generalized to other areas of the cerebellum, since we found considerably higher specificity in our population of recorded VPFL Golgi cells than was seen in OMV Golgi cells (Prsa et al., 2009). Although one would hope that Golgi cells play a similar role in the processing performed in these two areas, the differences seen between Golgi cells in VPFL and OMV may be a reflection of the different roles presumably played by these two areas in oculomotor control (Ilg and Thier, 2008). More experiments will be necessary to resolve this question.

\section{Origin of Golgi cell responses}

We found that Golgi cells had highly specific responses, suggesting the possibility that a small number of inputs with similar tuning define a Golgi cell's firing rate modulation. Additionally, we found that, consistent with earlier studies, the dominant response of Golgi cells is a pause in firing rate (Holtzman et al., 2006). It is difficult to reconcile these observations with classical descriptions of the cerebellar cortical microanatomy, wherein the dominant inputs are glutamatergic, via mossy and parallel fibers (Eccles et al., 1967; Palay and Chan-Palay, 1974). Moreover, assuming that the units we recorded simultaneously with Golgi cells were indeed mossy fibers, it is puzzling that the pairs were antiphasic. However, there are at least two mechanisms that can be invoked to explain these phenomena (Fig. 8). First, Golgi cells have been proposed to receive inhibitory input (via GABAergic and glycinergic synapses) from molecular layer interneurons, including basket and stellate cells (D'Angelo and De Zeeuw, 2009). Little is known about the synaptic efficacy of this inhibition, but if the molecular layer interneurons are driven by inputs with a similar tuning as the mossy fiber recorded simultaneously with the Golgi cell, they would presumably produce a Golgi cell pause in response to a mossy fiber burst. This action through a third player could explain the antiphasic relationship between the mossy fiber and Golgi cell. However, it is difficult to imagine how the tight correlation between the mossy fiber and Golgi cell could be maintained through a third player unless the same mossy fiber provides strong innervation of the molecular interneurons inhibiting the Golgi cell. Another possibility is that mossy fibers act directly on Golgi cells through an inhibitory mechanism mediated by mGluR2 receptor activation of G-protein coupled inward rectifying potassium (GIRK) channels (Watanabe and Nakanishi,
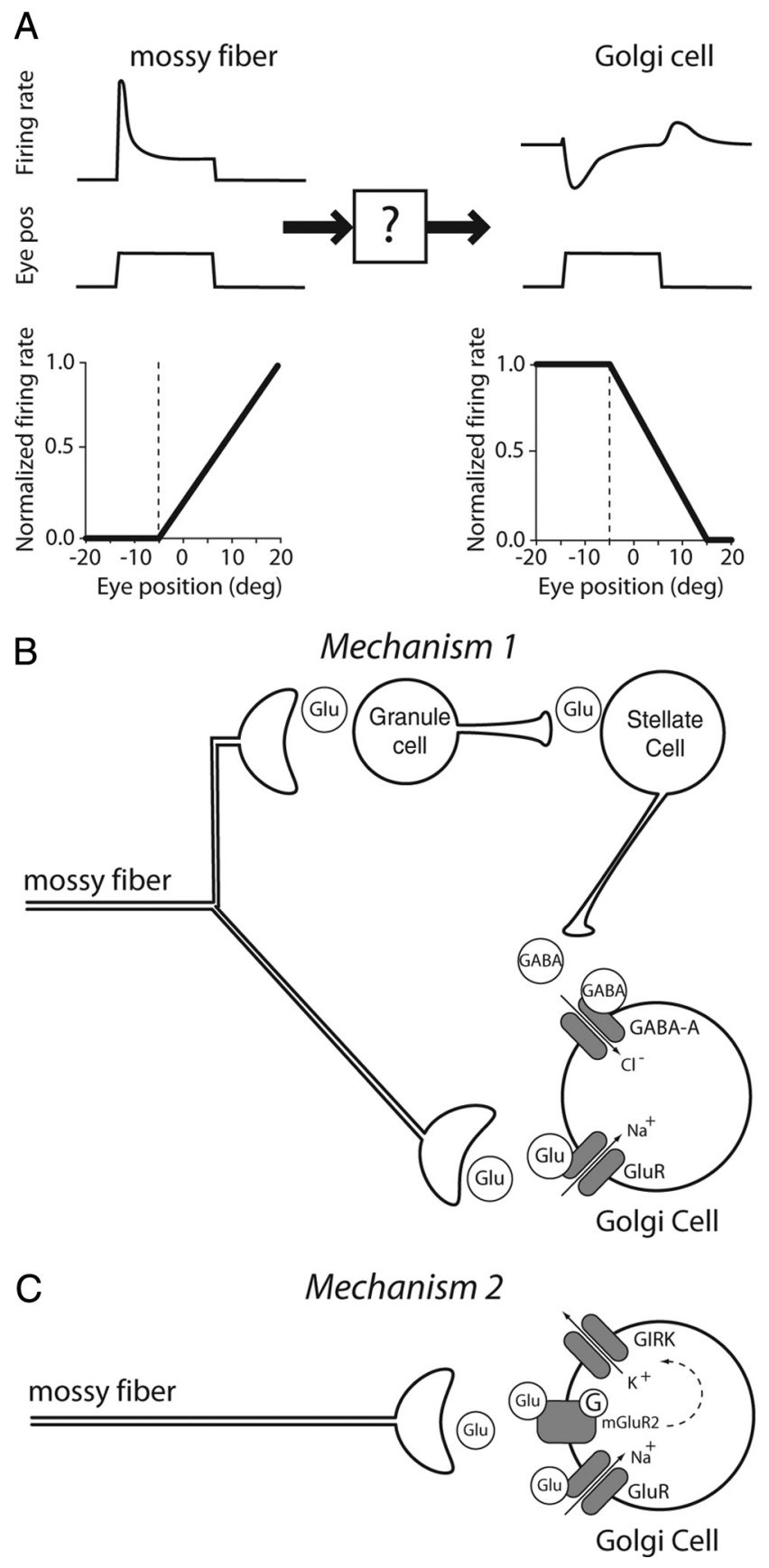

Figure 8. Plausible mechanisms to explain Golgicell responses. $A$, Left, Typical mossy fiber bursttonic response (top) to a change in eye position (pos) resulting from a saccade (middle) and hypothetical firing rate versus eye position curve (bottom). Vertical dashed line indicates mossy-fiber eye-position activation threshold. Right, Typical Golgi cell response for the same eye movement. Note that Golgi cell off response corresponds to mossy fiber burst and on response corresponds to mossy fiber pause. This antiphasic coupling results in the Golgi cell having an inverted eye position response range compared with the mossy fiber (dashed line). $\boldsymbol{B}, \boldsymbol{C}$, Two possible mechanisms to explain antiphasic coupling of mossy fiber and Golgi cell responses based on known connections and synaptic properties (see text). B, Mechanism 1, Indirect mossy fiber effect over Golgi cell via inhibitory interneurons receiving similarly tuned mossy fiber-granule cell input as Golgi cell. Glutamate (Glu) released from mossy fiber terminals activates ionotropic glutamate receptors (GluR) on Golgi cell and inhibitory interneuron, such as stellate cell. Stellate cell then releases inhibitory neurotransmitter, such as GABA, to generate a Golgi cell firing rate pause in response to mossy fiber burst. GluRactivation on the Golgi cell generates initial burst (ff. Fig. $4 A$ ) preceding the pause. C, Mechanism 2, Direct mossy fiber effect over Golgi cell via mGluR2 activation of GIRK channels. Glutamate released from mossy fiber terminals activates ionotropic and metabotropic glutamate (i.e., mGluR2) receptors on Golgi cell. The balance between inward current through GluR and outward current through GIRK determines net response of Golgi cell. 
2003). This is a similar mechanism to that of the mGluR6 receptors at the photoreceptor-bipolar cell synapse in the retina (Snellman et al., 2008). Interestingly, some of our Golgi cells occasionally showed a transient (1-2 spikes) burst in firing rate immediately preceding the pause, which could reflect activation of excitatory ionotropic glutamate receptors such as AMPA before the opening of the GIRK channels. Thus, the decreases in firing rate may result from a net dominance of mGluR2 receptormediated inhibition over AMPA and NMDA channel-mediated excitation. The long durations of the pauses found by us and others (Tahon et al., 2005; Holtzman et al., 2006) are supportive of this hypothesis, since a large proportion of mGluR2 receptors have nonsynaptic localizations (Luján et al., 1997) and are thus likely activated by glutamate spillover, which may take place in the glomeruli. A small number of mossy fibers could substantially influence the Golgi cell firing pattern, particularly if they act via large en marron synapses between mossy fiber rosettes and Golgi cell somata (Chan-Palay and Palay, 1971) or via glutamate spillover onto Golgi cell descending dendrites that participate in the glomeruli (Eccles et al., 1967). Kanichay and Silver (2008) have already provided electrophysiological evidence that a small number of mossy fibers can powerfully steer Golgi cell responses. In this scheme, the parallel fiber inputs may serve to synchronize the spontaneous spike times of on beam Golgi cells (Maex and De Schutter, 1998; Maex et al., 2000) rather than contributing significantly to moment-to-moment modulations in firing rate. Further investigation using pharmacological manipulation will be necessary to better understand the origin of the antiphasic relationship between Golgi cells and mossy fibers and the generation Golgi cell eye position fields.

\section{References}

Barmack NH, Yakhnitsa V (2008) Functions of interneurons in mouse cerebellum. J Neurosci 28:1140-1152.

Blazquez PM, Hirata Y, Heiney SA, Green AM, Highstein SM (2003) Cerebellar signatures of vestibulo-ocular reflex motor learning. J Neurosci 23:9742-9751.

Chadderton P, Margrie TW, Häusser M (2004) Integration of quanta in cerebellar granule cells during sensory processing. Nature 428:856-860.

Chan-Palay V, Palay SL (1971) The synapse en marron between golgi II neurons and mossy fibers in the rat's cerebellar cortex. Z Anat Entwicklungsgesch 133:274-287.

D’Angelo E, De Zeeuw CI (2009) Timing and plasticity in the cerebellum: focus on the granular layer. Trends Neurosci 32:30-40.

Dieudonne S (1998) Submillisecond kinetics and low efficacy of parallel fibre-Golgi cell synaptic currents in the rat cerebellum. J Physiol 510:845-866

Ebner TJ, Pasalar S (2008) Cerebellum predicts the future motor state. Cerebellum 7:583-588.

Eccles J, Llinas R, Sasaki K (1964) Golgi cell inhibition in the cerebellar cortex. Nature 204:1265-1266.

Eccles J, Ito M, Szentágothai J (1967) The cerebellum as a neuronal machine. Heidelberg: Springer.

Forti L, Cesana E, Mapelli J, D’Angelo E (2006) Ionic mechanisms of autorhythmic firing in rat cerebellar Golgi cells. J Physiol 574:711-729.

Ghasia FF, Meng H, Angelaki DE (2008) Neural correlates of forward and inverse models for eye movements: evidence from three-dimensional kinematics. J Neurosci 28:5082-5087.

Green AM, Meng H, Angelaki DE (2007) A reevaluation of the inverse dynamic model for eye movements. J Neurosci 27:1346-1355.

Holt GR, Softky WR, Koch C, Douglas RJ (1996) Comparison of discharge variability in vitro and in vivo in cat visual cortex neurons. J Neurophysiol 75:1806-1814.

Holtzman T, Rajapaksa T, Mostofi A, Edgley SA (2006) Different responses of rat cerebellar Purkinje cells and Golgi cells evoked by widespread convergent sensory inputs. J Physiol 574:491-507.
Ilg UJ, Thier P (2008) The neural basis of smooth pursuit eye movements in the rhesus monkey brain. Brain Cogn 68:229-240.

Kanichay RT, Silver RA (2008) Synaptic and cellular properties of the feedforward inhibitory circuit within the input layer of the cerebellar cortex. J Neurosci 28:8955-8967.

Langer T, Fuchs AF, Scudder CA, Chubb MC (1985) Afferents to the flocculus of the cerebellum in the rhesus macaque as revealed by retrograde transport of horseradish peroxidase. J Comp Neurol 235:1-25.

Lisberger SG, Fuchs AF (1978a) Role of primate flocculus during rapid behavioral modification of vestibuloocular reflex. I. Purkinje cell activity during visually guided horizontal smooth-pursuit eye movements and passive head rotation. J Neurophysiol 41:733-763.

Lisberger SG, Fuchs AF (1978b) Role of primate flocculus during rapid behavioral modification of vestibuloocular reflex. II. Mossy fiber firing patterns during horizontal head rotation and eye movement. J Neurophysiol 41:764-777.

Luján R, Roberts JD, Shigemoto R, Ohishi H, Somogyi P (1997) Differential plasma membrane distribution of metabotropic glutamate receptors mGluR1 alpha, mGluR2 and mGluR5, relative to neurotransmitter release sites. J Chem Neuroanat 13:219-241.

Maex R, De Schutter E (1998) Synchronization of golgi and granule cell firing in a detailed network model of the cerebellar granule cell layer. J Neurophysiol 80:2521-2537.

Maex R, Vos BP, De Schutter E (2000) Weak common parallel fibre synapses explain the loose synchrony observed between rat cerebellar golgi cells. J Physiol 523:175-192.

Miles FA, Fuller JH, Braitman DJ, Dow BM (1980) Long-term adaptive changes in primate vestibuloocular reflex. III. Electrophysiological observations in flocculus of normal monkeys. J Neurophysiol 43:1437-1476.

Mustari MJ, Fuchs AF, Wallman J (1988) Response properties of dorsolateral pontine units during smooth pursuit in the rhesus macaque. J Neurophysiol 60:664-686.

Nakamagoe K, Iwamoto Y, Yoshida K (2000) Evidence for brainstem structures participating in oculomotor integration. Science 288:857-859.

Noda H (1986) Mossy fibres sending retinal-slip, eye, and head velocity signals to the flocculus of the monkey. J Physiol 379:39-60.

Noda H, Warabi T (1987) Responses of Purkinje cells and mossy fibres in the flocculus of the monkey during sinusoidal movements of a visual pattern. J Physiol 387:611-628.

Palay S, Chan-Palay V (1974) Cerebellar cortex cytology and organization. New York: Springer.

Pasalar S, Roitman AV, Durfee WK, Ebner TJ (2006) Force field effects on cerebellar Purkinje cell discharge with implications for internal models. Nat Neurosci 9:1404-1411.

Prsa M, Dash S, Catz N, Dicke PW, Thier P (2009) Characteristics of responses of Golgi cells and mossy fibers to eye saccades and saccadic adaptation recorded from the posterior vermis of the cerebellum. J Neurosci 29:250-262.

Ramon y Cajal S (1911) Histologie du systeme nerveux de l'home et des vertebras. Paris: Maloine.

Shin SL, Hoebeek FE, Schonewille M, De Zeeuw CI, Aertsen A, De Schutter E (2007) Regular patterns in cerebellar Purkinje cell simple spike trains. PLoS One 2:e485.

Simpson JI, Hulscher HC, Sabel-Goedknegt E, Ruigrok TJ (2005) Between in and out: linking morphology and physiology of cerebellar cortical interneurons. Prog Brain Res 148:329-340.

Snellman J, Kaur T, Shen Y, Nawy S (2008) Regulation of ON bipolar cell activity. Prog Retin Eye Res 27:450-463.

Tahon K, Volny-Luraghi A, De Schutter E (2005) Temporal characteristics of tactile stimuli influence the response profile of cerebellar Golgi cells. Neurosci Lett 390:156-161.

Thach WT (1968) Discharge of Purkinje and cerebellar nuclear neurons during rapidly alternating arm movements in the monkey. J Neurophysiol 31:785-797.

Vos BP, Volny-Luraghi A, De Schutter E (1999) Cerebellar Golgi cells in the rat: receptive fields and timing of responses to facial stimulation. Eur J Neurosci 11:2621-2634.

Watanabe D, Nakanishi S (2003) mGluR2 postsynaptically senses granule cell inputs at Golgi cell synapses. Neuron 39:821-829. 